\title{
The relationship between tooth loss, body mass index, and hypertension in postmenopausal female
}

\author{
Basma Ezzat Mustafa Al-Ahmad ${ }^{1}$, Muhannad Ali Kashmoola ${ }^{2}$, Nazih Shaaban Mustafa $^{2}$, \\ Haszelini Hassan ${ }^{2}$, Mohd Hafiz Arzmi ${ }^{1}$
}

Correspondence: Dr. Basma Ezzat Mustafa Al-Ahmad

Email: drbasma@iium.edu.my

\begin{abstract}
'Department of Fundamental Basic Dental Sciences, Kulliyyah of Dentistry, International Islamic University Malaysia, Selangor, Malaysia,

2Department of Oral Maxillofacial Surgery and Oral Diagnosis, Kulliyyah of Dentistry, International Islamic University Malaysia, Selangor, Malaysia
\end{abstract}

\section{ABSTRACT}

Objective: This study aimed to investigate the relationship between tooth loss and the level of blood pressure with the hypothesis that tooth loss is associated with the increase of hypertension in postmenopausal women. Materials and Methods: Sixty postmenopausal female patients aged 51-68 years were included in the study to assess the relationship between tooth loss and the level of blood pressure. The information including sociodemographics, last menstruation period, hypertension history, and the duration of having tooth loss was recorded. Blood pressure was measured using sphygmomanometer and the number of tooth loss was determined. Results: The results showed a more significant tooth loss in hypertension (median: $23+4$; interquartile range [IQR]: 6 ) compared to the normotension postmenopausal women (median: $18+6$; IQR: 12; $P<0.05$ ). Furthermore, obese patients had more tooth loss (median: 23+5; IQR: 8) than the overweight patients (median: 19+8; IQR: 8). Conclusion: Tooth loss is associated with the increase of hypertension in postmenopausal women which may have a role in the development of vascular diseases.

Key words: Blood pressure, body mass index, hypertension, postmenopause, tooth loss

\section{INTRODUCTION}

Tooth loss is defined as separation of tooth from its supporting structure that can be caused by tooth caries, periodontal disease, periapical infection, fractured tooth, and failure of endodontic treatment. ${ }^{[1,2]}$ It can affect the physical and social lifestyle of a patient that may have a role in increased risk of hypertension. ${ }^{[3]}$ Hypertension is defined as an abnormal elevation of systolic and/or diastolic arterial pressures above the normal range. ${ }^{[4]}$ The normal ranges of systolic and diastolic arterial pressures are determined at 100-140 mmHg and 60-100 mmHg, respectively. ${ }^{[5]}$

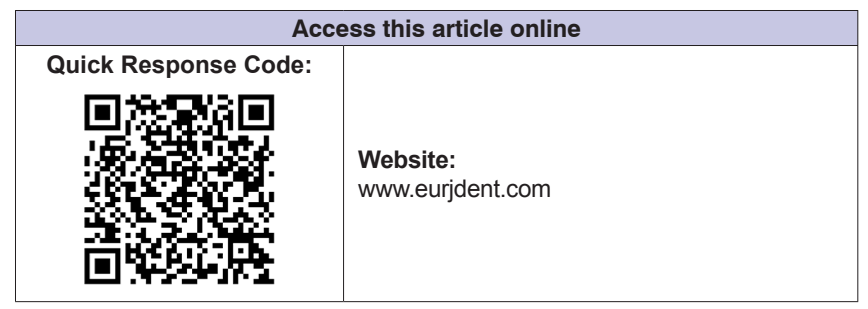

Complete edentulism has been shown to be associated with the development of hypertension. ${ }^{[6]}$ A previous study showed that the means of systolic and diastolic blood pressures were higher in patients with complete edentulism compared to fully dentate patients. ${ }^{[7]}$ Moreover, a study conducted in Brazil showed that the edentulous individuals had higher systolic blood pressure than the individuals who possessed $>10$ teeth in both arches. ${ }^{[8]}$

Tooth loss has been reported to associate with the increase of cardiovascular diseases. ${ }^{[9]}$ A cohort study of

This is an open access article distributed under the terms of the Creative Commons Attribution-NonCommercial-ShareAlike 3.0 License, which allows others to remix, tweak, and build upon the work non-commercially, as long as the author is credited and the new creations are licensed under the identical terms.

For reprints contact: reprints@medknow.com

How to cite this article: Al-Ahmad BE, Kashmoola MA,
Mustafa NS, Hassan H, Arzmi MH. The relationship between tooth loss,
body mass index, and hypertension in postmenopausal female. Eur J
Dent 2018;12:120-2.
Dol: 10.4103/ejd.ejd_322_17
body mass index, and hypertension in postmenopausal female. Eur $\mathrm{J}$ DOI: 10.4103/ejd.ejd_322_17 
7674 patients followed for 12 years showed that there was a 7-fold increase of mortality risk from coronary heart disease in patients with $<10$ teeth compared to those with $>25$ teeth. ${ }^{[9]}$ Furthermore, patients with $<25$ teeth at baseline have reported to possess higher risk for getting stroke compared to the patients with $>25$ teeth. ${ }^{[10]}$ A study has also shown that edentulous women had a greater risk of obesity, lower high-density lipoprotein (HDL)-cholesterol level, and higher total cholesterol and triglyceride level when compared to the dentate women, which may lead to the development of hypertension and cardiovascular diseases. ${ }^{[11]}$

The objective of the present study is to investigate the relation between tooth loss and hypertension in postmenopausal women with the hypothesis that hypertension is associated with tooth loss in postmenopausal women.

\section{MATERIALS AND METHODS}

\section{Sample selection}

A total of 60 female patients aged 51-68 years attending Polyclinic, Kulliyyah of Dentistry, International Islamic University Malaysia, were included in this study. The patients were divided into two groups, which comprised (1) 26 postmenopausal female patients with hypertension and (2) 34 postmenopausal female patients without hypertension (normotension). Postmenopausal female patients without hypertension served as the negative control for the study. The inclusion criteria were postmenopausal women aged 51-68 years and having tooth loss after menopause. The exclusion criteria for the research were smokers, those with renal impairment, liver disorder, and trauma in jaw, and patients on hormone replacement therapy.

\section{Data collection}

For the data collection, patients were interviewed and the information including sociodemographics, last menstruation period, family history of hypertension, and duration of having tooth lost was recorded.

\section{Physical and clinical examination}

Physical examination was conducted by measuring the blood pressure of each patient using sphygmomanometer. The blood pressure of patient who came for tooth extraction was measured before and after the procedure. The blood pressure of patient who came for scaling, restoration, and any other treatment which were not involved in surgical procedure was measured during the first visit. Body mass index (BMI) was also measured using a measuring tape and a weighing scale. Finally, clinical examination was conducted to determine the presence of tooth loss.

\section{Data analysis}

All data were statistically analyzed using nonparametric Mann-Whitney test to compare the relationship of tooth loss and hypertension using SPSS 19.0 (IBM SPSS Statistics for Windows, IBM Corp: Armonk, NY). Nonparametric statistical analysis was conducted on the samples that were not normally distributed. The data were considered statistically significant when $P<0.05$.

\section{RESULTS}

A more significant tooth loss was observed in postmenopausal women with hypertension compared to normotension $[P<0.05$; Figure 1]. The results of the present study also showed that postmenopausal women with obesity had more tooth loss than the overweight [Figure 2]. The median value of tooth loss for normotension group was lower than the hypertension group [Table 1]. Even though both groups had the same maximum number of tooth loss, the minimum number of tooth loss in normotension was less than the hypertension group [Table 1].

The interquartile range value of tooth loss of the overweight and obese was observed to be similar; however, the median value for obese group was found to be higher than the overweight [Table 1]. Finally, there was no significant different between age and hypertension status $(P>0.05)$, which indicated that age factor may not contribute to the development of hypertension in postmenopausal women.

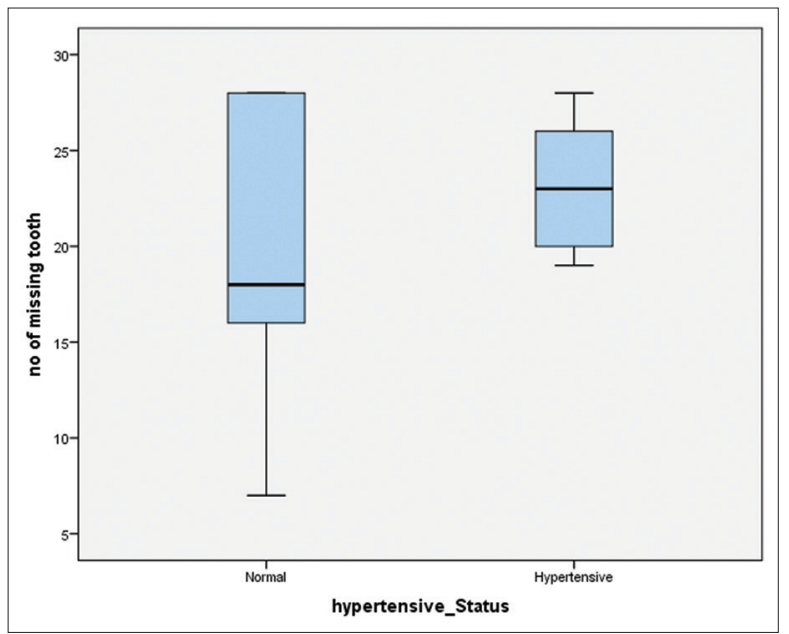

Figure 1: Relationship between number of missing tooth and hypertensive status. 


\section{DISCUSSION}

To our knowledge, this is the first study conducted in Malaysia to determine the role of tooth loss to hypertension among postmenopausal women. The present study showed that hypertensive women had more tooth loss compared to normotensive women after adjustment of the age of the patients. This finding supported the hypothesis of the study that tooth loss is associated with the increase of hypertension in postmenopausal women. Previous research has shown that postmenopausal women with missing teeth had higher systolic blood pressure than those without missing teeth. ${ }^{[4]}$ Based on Cox regression analyses conducted by Liljestrand et al., patients who had tooth loss of more than five will have $140 \%$ increased hazard of acute myocardial infection and coronary heart disease, suggesting that postmenopausal women with higher number of tooth loss are more likely to have cardiac diseases. ${ }^{[1]}$

The present study also showed that more tooth loss was observed in obese patients than the overweight. Obesity has been reported to have a role in the development of hypertension and vascular diseases. ${ }^{[12]}$ A previous study has also shown that postmenopausal women with missing teeth together with high BMI, high cholesterol, HDL-cholesterol, triglycerides, and low-density lipoprotein-cholesterol had a higher chance

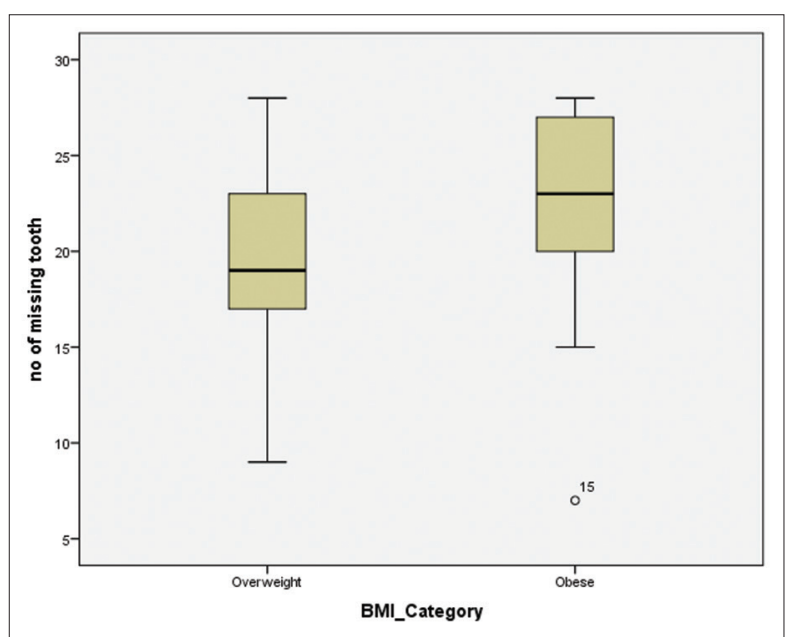

Figure 2: The relationship between number of missing tooth and BMI status

\begin{tabular}{|c|c|c|}
\hline Number of tooth loss & Median & Interquartile range (IQR) \\
\hline Normotensive & $18 \pm 6$ & 12 \\
\hline Hypertensive & $23 \pm 4$ & 6 \\
\hline Overweight & $19 \pm 8$ & 8 \\
\hline Obese & $23 \pm 5$ & 8 \\
\hline
\end{tabular}

to have vascular diseases compared to those without missing teeth. ${ }^{[4,9]}$ Further study is recommended by increasing the sample size to determine the relation of tooth loss to postmenopausal female patients.

\section{CONCLUSION}

There is a relationship between tooth loss and hypertension in postmenopausal female with more tooth loss in hypertensive patients than normotensive patients that may have a role in the development of vascular diseases.

\section{Acknowledgment}

We would like to acknowledge those who had contributed in our research; Aishah Badihah Azni, Farah Izzati Azmi, Ezatul Fariha Zakaria.

Financial support and sponsorship

This research was supported by the Research Initiative Grant Scheme (RIGS 16324 0488).

\section{Conflicts of interest}

There are no conflicts of interest.

\section{REFERENCES}

1. Liljestrand JM, Havulinna AS, Paju S, Männistö S, Salomaa V, Pussinen PJ, et al. Missing teeth predict incident cardiovascular events, diabetes, and death. J Dent Res 2015;94:1055-62.

2. López-Gómez SA, Villalobos-Rodelo JJ, Ávila-Burgos L, Casanova-Rosado JF, Vallejos-Sánchez AA, Lucas-Rincón SE, et al. Relationship between premature loss of primary teeth with oral hygiene, consumption of soft drinks, dental care, and previous caries experience. Sci Rep 2016;6:21147.

3. Kassebaum NJ, Bernabé E, Dahiya M, Bhandari B, Murray CJ, Marcenes W, et al. Global burden of severe tooth loss: A Systematic review and meta-analysis. J Dent Res 2014;93:20S-8S.

4. TaguchiA, SanadaM,SueiY,OhtsukaM,LeeK, TanimotoK, etal. Toothloss is associated with an increased risk of hypertension in postmenopausal women. Hypertension 2004;43:1297-300.

5. Akmandor AO, Jha NK. Keep the stress away with soda: Stress detection and alleviation system. IEEE Trans Multi Scale Comput Syst2017;3:269-82. Available from: http://www.ieeexplore.ieee.org/ abstract/document/7926455/. [Last accessed on 2017 Dec 02].

6. Völzke H, Schwahn C, Dörr M, Schwarz S, Robinson D, Dören M, et al. Gender differences in the relation between number of teeth and systolic blood pressure. J Hypertens 2006;24:1257-63.

7. Ayo-Yusuf OA, Ayo-Yusuf IJ. Association of tooth loss with hypertension. S Afr Med J 2008;98:381-5.

8. Peres MA, Tsakos G, Barbato PR, Silva DA, Peres KG. Tooth loss is associated with increased blood pressure in adults - A multidisciplinary population-based study. J Clin Periodontol 2012;39:824-33.

9. Holmlund A, Holm G, Lind L. Number of teeth as a predictor of cardiovascular mortality in a cohort of 7,674 subjects followed for 12 years. J Periodontol 2010;81:870-6.

10. Joshipura KJ, Hung HC, Rimm EB, Willett WC, Ascherio A. Periodontal disease, tooth loss, and incidence of ischemic stroke. Stroke 2003;34:47-52.

11. Österberg T, Dey DK, Sundh V, Carlsson GE, Jansson JO, Mellström D, et al. Edentulism associated with obesity: A study of four national surveys of 16416 swedes aged 55 \& \#x2013;84 years. Acta Odontol Scand 2010;68:360-7.

12. Alpert MA, Omran J, Mehra A, Ardhanari S. Impact of obesity and weight loss on cardiac performance and morphology in adults. Prog Cardiovasc Dis 2014;56:391-400. 